\title{
Induced sensitivity of Bacillus subtilis colony morphology to mechanical media compression
}

Bacteria from several taxa, including Kurthia zopfii, Myxococcus xanthus, and Bacillus mycoides, have been reported to align growth of their colonies to small features on the surface of solid media, including anisotropies created by compression. While the function of this phenomenon is unclear, it may help organisms navigate on solid phases, such as soil. The origin of this behavior is also unknown: it may be biological (that is, dependent on components that sense the environment and regulate growth accordingly) or merely physical. Here we show that $B$. subtilis, an organism that typically does not respond to media compression, can be induced to do so with two simple and synergistic perturbations: a mutation that maintains cells in the swarming (chained) state, and the addition of EDTA to the growth media, which further increases chain length. EDTA apparently increases chain length by inducing defects in cell separation, as the treatment has only marginal effects on the length of individual cells. These results lead us to three conclusions. First, the wealth of genetic tools available to $B$. subtilis will provide a new, tractable chassis for engineering compression sensitive organisms. Second, the sensitivity of colony morphology to media compression in Bacillus can be modulated by altering a simple physical property of rodshaped cells. And third, colony morphology under compression holds promise as a rapid, simple, and low-cost way to screen for changes in the length of rod-shaped cells or chains thereof. 


\section{Induced sensitivity of Bacillus subtilis colony morphology 2 to mechanical media compression}

4 Jessica K. Polka ${ }^{1,2}$ and Pamela A. Silver ${ }^{1,2}$ *

5 1. Systems Biology Department, Harvard Medical School

62 2. Wyss Institute for Biologically Inspired Engineering, Harvard University

$7 \quad *$ To whom correspondence should be addressed

\section{ABSTRACT}

9 Bacteria from several taxa, including Kurthia zopfii, Myxococcus xanthus, and

10 Bacillus mycoides, have been reported to align growth of their colonies to small

11 features on the surface of solid media, including anisotropies created by

12 compression. While the function of this phenomenon is unclear, it may help

13 organisms navigate on solid phases, such as soil. The origin of this behavior is also

14 unknown: it may be biological (that is, dependent on components that sense the 15 environment and regulate growth accordingly) or merely physical.

16 Here we show that $B$. subtilis, an organism that typically does not respond to media 17 compression, can be induced to do so with two simple and synergistic perturbations: 18 a mutation that maintains cells in the swarming (chained) state, and the addition of 19 EDTA to the growth media, which further increases chain length. EDTA apparently 20 increases chain length by inducing defects in cell separation, as the treatment has 21 only marginal effects on the length of individual cells.

22 These results lead us to three conclusions. First, the wealth of genetic tools available 23 to $B$. subtilis will provide a new, tractable chassis for engineering compression

24 sensitive organisms. Second, the sensitivity of colony morphology to media 25 compression in Bacillus can be modulated by altering a simple physical property of 26 rod-shaped cells. And third, colony morphology under compression holds promise as 27 a rapid, simple, and low-cost way to screen for changes in the length of rod-shaped 28 cells or chains thereof. 
30 Response of bacterial colony morphology (ie, orientation of growth) to small

31 mechanical perturbations of growth media was first noted in Kurthia, a gram-positive

32

33

34

35

36

37

\section{Time lapse microscopy}

$2 \%$ LB agar was cut into approximately $10 \mathrm{~mm} \times 10 \mathrm{~mm}$ squares and inoculated with genus notable for its striking feather-like morphology on gelatin slant cultures. (Sergent, 1906, 1907; Jacobsen, 1907; Stackebrandt, Keddie \& Jones, 2006) A similar compression response has been reported in Myxococcus xanthus, where the phenomenon is dependent on adventurous motility, a flagellum- and piliindependent movement system.(Stanier, 1942; Fontes \& Kaiser, 1999; Nan et al., 2014) Recently, the soil bacterium Bacillus mycoides was also shown to be sensitive to media perturbations.(Stratford, Woodley \& Park, 2013) Interestingly, this compression response seems to occur by two different mechanisms: whereas individual Myxococcus xanthus dynamically reorients individual cells along lines of compression,(Dworkin, 1983) Bacillus mycoides instead gradually reorients the tips of chained cells as it grows. (Stratford et al., 2013)

The function of compression response is not known, but it has been suggested to aid navigation in natural environments on solid phases, like soil.(Dworkin, 1983) It has also been proposed as a potential tool for engineering applications in sensing environmental forces or generating patterns for nanofabrication.(Stratford et al., 2013)

Here we investigate whether increasing the length of chains of cells can induce compression sensitivity in an otherwise compression-insensitive species, $B$. subtilis. We employ a mutant of $B$. subtilis that forms long chains of cells (much like $B$. mycoides) and also deplete divalent cations in the media with EDTA; $\mathrm{Mg}^{2+}$ is thought be important for cell wall integrity. $B$. subtilis deprived of magnesium accumulates cell wall precursors, (Garrett, 1969) and magnesium is known to bind to components of the cell wall.(Heckels, Lambert \& Baddiley, 1977) Notably, high magnesium concentrations can restore rod shape to cells with mutations in MreB, MreD, and PonA - all genes involved in cell wall synthesis. (Rogers, Thurman \& Buxton, 1976; Rogers \& Thurman, 1978; Murray, Popham \& Setlow, 1998; Formstone \& Errington, 2005) $1 \mu \mathrm{l}$ of liquid culture. The pad was then wedged, in a glass-bottomed dish (P35G-1.520-C, MatTek Corp.), between two plastic coverslips (Rinzl Plastic Coverslips, Size $22 \times 22 \mathrm{~mm}$, Electron Microscopy Science) manually bent in half at a $90^{\circ}$ angle. Thus, half of each plastic coverslip made contact with the bottom of the dish, while the other half made contact with the agar pad. After placing a drop of approximately $50 \mu \mathrm{l}$ of water on top of each plastic coverslip to maintain humidity in the dish, the MatTek dish was sealed with parafilm (this setup is illustrated in Fig. 1A). Cells (table 1 ) were grown for approximately 6 hours at room temperature (approximately $23^{\circ}$ ) during a timelapse acquisition on a Nikon TE 2000 microscope equipped with an Orca ER camera, a 20x phase contrast objective, and Perfect Focus. A large area of 
72 the sample was composited with automatic image stitching by Nikon Elements AR.

73 Areas toward the center of the pad were selected for imaging.

\section{Plate compression}

75 Microtiter format plates were prepared with LB $+2 \%$ agar. 24 hours after plates

76 were poured, sterilized polystyrene spacers (each 0.080 " thick, for a total

77 compression of $0.16^{\prime \prime}$ or $4.1 \mathrm{~mm}$, equivalent to $4.8 \%$ compression) were inserted

78 along the long dimension. Plates were stored at $37^{\circ}$ for 24 hours, then inoculated

79 from colonies grown on LB agar. Plates were incubated for $2-3$ days at $30^{\circ}$, as the

80 time required to reach colony dimensions $>8 \mathrm{~mm}$ varied with EDTA concentration.

81 After incubation, plates were imaged with a gel imager and colony dimensions

82 measured with FIJI.(Schindelin et al., 2012)

\section{Cellular morphology}

84 Colonies were grown on LB $+2 \%$ agar containing either 0 or $125 \mu \mathrm{M}$ EDTA. After 24

85 hours of incubation at $30^{\circ}$, cells from the edges of colonies were transferred directly

86 to LB $+2 \%$ agar pads for imaging with the rounded bottoms of $0.6 \mu$ l centrifuge

87 tubes. To each pad, $1 \mu \mathrm{l}$ of an aqueous solution containing $10 \mu \mathrm{g} / \mathrm{ml} \mathrm{FM4-64}$

88 (Invitrogen) was added. Cells were imaged with a 100X phase contrast objective,

89 and cell and chain lengths were measured manually with spline-fitted segmented

90 lines in FIJI. Two-sample KS tests were performed.(Kirkman, 1996)

91

92

93

94

95

96

97

98

99

100

101

102

103

104

105

106

107

108

109

110

111

112

113

\section{RESULTS}

We first noted weak compression response of $B$. subtilis under the microscope. Unlike $B$. mycoides, $B$. subtilis colonies remain circular under compression under normal conditions. However, our microscopy assay (Fig. 1A) revealed that at small length scales $(<100 \mu \mathrm{m}), B$. subtilis cells display short-range alignment perpendicular to the direction of compression (marked with black arrows in Fig. 1AC). Noting that the alignment is disrupted over longer length scales, we sought conditions under which $B$. subtilis cells might behave more similarly to $B$. mycoides. We noted that the chains of $B$. subtilis PY79 appeared shorter than that of $B$. mycoides, with the former reaching a maximum of approximately $300 \mu \mathrm{m}$ (Fig. 1C), while the can extend for millimeters(Stratford et al., 2013).

To increase chain length, we used $B$. subtilis $\sigma^{D}:$ :tet, a mutant that does not switch from swimming to swarming motility, and thus grows in long chains of cells (Kearns \& Losick, 2005). To further perturb cell separation, we added EDTA to the growth medium.

To study colony morphology of $B$. subtilis under compression at the macroscopic scale with reproducible compression conditions, we prepared microtiter plates with $\mathrm{LB}+2 \%$ agar and wedged polystyrene spacers between the agar and an edge of the plates (Fig. 2A). We inoculated the agar with colonies of $B$. mycoides, $B$. subtilis PY79, and $B$. subtilis $\sigma^{\mathrm{D}}$ ::tet. Under $4.8 \%$ compression, $B$. mycoides forms elongated colonies as reported,(Stratford et al., 2013) while, without EDTA, B. subtilis colonies are round (Fig. 2A). With the addition of EDTA to the media, both B. subtilis PY79 and $\sigma^{\mathrm{D}}$ ::tet display a compression response (Fig. 2B). This is dependent on the 
114 degree of compression; at $2.4 \%$ compression, both $B$. subtilis strains formed round 115 colonies (data not shown).

116 We next quantified this effect over several colonies under each EDTA condition at $1174.8 \%$ compression. Bacillus mycoides forms colonies 4-4.5x larger in the dimension 118 perpendicular to the direction of compression than parallel to it regardless of EDTA 119 concentration (Fig. 2C). In comparison, the effect in B. subtilis is relatively small, and 120 this effect scaled with EDTA concentration (Fig. 2C). The EDTA effect was stronger

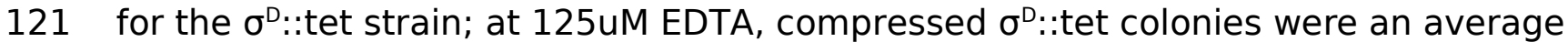
122 of $1.64 x$ larger in the direction of compression $(n=17$, standard deviation 0.21 ), 123 while PY79 colonies were an average of $1.23 x$ larger $(n=16$, standard deviation 124 0.20). While the difference in colony size ratio between 0 and 125uM EDTA for PY79 125 is significant by a two-tail t-test $(p<0.02)$, the difference between these 126 concentrations for $\sigma D$ ::tet is highly significant $(p<0.00001)$.

127 Furthermore, colonies from all three strains, but especially $B$. subtilis PY79 and $B$.

128 mycoides, grow at slower rates with increased EDTA concentration. The difference in

129

130

131 growth rate on EDTA may be attributable either to species- and strain-specific sensitivity to EDTA, or (in the case of PY79 and $\sigma D:$ :tet) to differences in sensitivity between swimming and swarming cells.

132 To understand how EDTA could affect compression response, we imaged cells taken 133 directly from the edges of colonies on solid media containing either $0 \mu \mathrm{M}$ (Fig. 3A-C) 134 or $125 \mu$ M EDTA (Fig. 3D-F). The chains of $B$. subtilis cells, both PY79 and $\sigma^{D}:$ :tet, are 135 longer on $125 \mu \mathrm{M}$ EDTA, but cell lengths, as delineated by the membrane dye FM4136 64, are only marginally different. Quantification of $\sim 300$ chain and cell lengths for 137 each strain under each condition (Fig. 4) reveals that $B$. subtilis chain lengths 138 increase dramatically with the presence of EDTA, while $B$. mycoides chain lengths 139 decrease slightly, suggesting that the EDTA effect on cell separation is specific to $B$. 140 subtilis (Table 2).

141

142

143

144

145

146

147

148

149

150

151

152

153

154

155

156

157

\section{DISCUSSION}

These results suggest that the phenomenon of colony orientation under compression can be induced in the model organism B. subtilis. In contrast to Bacillus mycoides (the transformation of which has been reported only anecdotally in the literature ( $\mathrm{Di}$ Franco et al., 2002)), the genetic tractability of $B$. subtilis will facilitate engineering of compression sensitive bacteria for use as environmental sensors or guides for nanofabrication.(Stratford et al., 2013)

Furthermore, the fact that that colony orientation on compressed media is generalizable indicates that it is likely to be a physical phenomenon. While we cannot exclude the involvement of biological components, any such components are certainly not exclusive to $B$. mycoides. Furthermore, the A-motility required for compression response in myxobacteria is not a requirement for all types of compression response.(Nan et al., 2014) Instead, it is likely that this compression response requires physical factors like rod length, surface friction, cell stiffness, and tip vs. isotropic growth pattern.

Long rod length is a common feature of two prototypical compression responders, Bacillus mycoides and Kurthia sp., which both grow as long chains of cells. (Di Franco

PeerJ reviewing PDF | (v2014:08:2517:1:0:NEW 3 Sep 2014) 
158 et al., 2002; Stackebrandt et al., 2006) As seen in microscopy of B. mycoides, the 159 absence of cell separation allows the bacteria to find and maintain a direction of 160 compression. This same chaining property is responsible for the baroque colony 161 morphology of $B$. mycoides: mutants that do not display this colony morphology 162 have shorter chain lengths.(Di Franco et al., 2002) Thus, compression response may 163 be driven by the same mechanisms that influence colony morphology under normal 164 conditions; these mechanisms influence the manner in which cells explore and 165 colonize their environment, and may be of critical importance in soil environments.

166 In the case of $B$. subtilis, the increase in compression sensitivity is based on chain 167 length (as a $\sigma^{\mathrm{D}}$ mutant responds more than PY79, and both respond more strongly in 168 the presence of EDTA, which also increases rod length). Though EDTA likely affects 169 multiple cellular processes, the role of $\mathrm{Mg}^{2+}$ in cell wall formation is clear. (Formstone 170 \& Errington, 2005) In particular, peptidoglycan hydrolases called autolysins are 171 implicated in separation of cells after septation. Some of these autolysins, such as 172 LytC, D, and F, are under the control of $\sigma^{D}$.(Chen et al., 2009) However, LytC 173 expression can also be driven by $\sigma^{A}$,(Lazarevic et al., 1992) and this 50kDa amidase 174 is activated by addition of $\mathrm{Mg} 2+$ in vitro.(Foster, 1992) We speculate that this 175 magnesium dependence of LytC and its regulation by a second sigma factor may 176 explain why EDTA treatment further increases chain length in $\sigma^{\mathrm{D}}$ ::tet cells. In 177 addition to LytC, EDTA may be acting on other autolysins not regulated by $\sigma^{\mathrm{D}}$ (such 178 as LytE or YwbG).(Smith, Blackman \& Foster, 2000) The insensitivity of B. mycoides 179 chain length to EDTA (Fig. 4, table 2) may be explained by species-specific 180 differences in autolysins.

181 Inhibition of cell separation may not be the only relevant effect of EDTA, however. 182 For example, perhaps depletion of $\mathrm{Mg}^{2+}$ changes the rigidity of cells such that they 183 more readily align with the isotropic agar surface (Fig. 1B). An exhaustive

184 understanding of EDTA's effects on the mechanical properties of $B$. subtilis walls, as 185 well as a mechanistic understanding of how it increases chain length, remains to be 186 attained.

187 The relatively weak maximal compression response we achieved with $B$. subtilis 188 189 190 191

192

193

194

195

196

197

198

199

200

201

202

203

204 compared to $B$. mycoides suggests that factors other than chain formation limit the compression response of $B$. subtilis. Indeed, filament or chain formation alone must not be sufficient for compression response, as some fungi and actinomycetes grow with this morphology but do not display the response.(Stratford et al., 2013) We suggest that friction with the agar surface may play a significant role. In micrographs of $B$. subtilis under compression, the chains of cells appear more buckled than those of $B$. mycoides (Fig. 1C); perhaps friction prevents the distal ends of the chain from sliding along to accommodate new growth from the middle of the chain. This buckling disrupts adjacent chains and is likely to lead to a more disorganized colony morphology. By contrast, $B$. mycoides chains elongate at a rate of $0.5 \mathrm{~mm}$ per hour, suggesting that the cells at the tip of the chain are being pushed forward by growth from the middle of the chain. (Stratford et al., 2013) In the future, further modifications, perhaps increasing surfactin production, may increase the magnitude of this response in $B$. subtilis. Additionally, we note that another contributing factor may be the growth pattern of this organism. Whereas $B$. mycoides elongates from its tips, (Turchi et al., 2012) B. subtilis inserts cell wall isotropically along its length. (Tiyanont et al., 2006) 
205

206

207

208

209

210

211

212

213

214

215

225

226

227

228

229

230

Finally, because $B$. subtilis compression response depends on chain length, we propose that under some circumstances, colony morphology under compression could serve as a simple, high-throughput assay for perturbations to bacterial cell length and chain formation.

\section{ACKNOWLEDGEMENTS}

We thank Ethan Garner (Harvard University), Michael Baym (Harvard Medical School) and Ariel Amir (Harvard University) for helpful discussions. We are grateful to Stephanie Hays (Harvard Medical School) for critical reading of the manuscript, and to James P Stratford (Nottingham) and two anonymous reviewers for their insightful comments.

\section{REFERENCES}

Chen R, Guttenplan SB, Blair KM, Kearns DB. 2009. Role of the oD-Dependent Autolysins in Bacillus subtilis Population Heterogeneity. Journal of Bacteriology 191:5775-5784.

Dworkin M. 1983. Tactic behavior of Myxococcus xanthus. Journal of Bacteriology 154:452-459.

Fontes M, Kaiser D. 1999. Myxococcus cells respond to elastic forces in their substrate. Proceedings of the National Academy of Sciences 96:8052-8057.

Formstone A, Errington J. 2005. A magnesium-dependent mreB null mutant: implications for the role of mreB in Bacillus subtilis. Molecular Microbiology 55:1646-1657.

Foster SJ. 1992. Analysis of the autolysins of Bacillus subtilis 168 during vegetative growth and differentiation by using renaturing polyacrylamide gel electrophoresis. Journal of Bacteriology 174:464-470.

Di Franco C, Beccari E, Santini T, Pisaneschi G, Tecce G. 2002. Colony shape as a genetic trait in the pattern-forming Bacillus mycoides. BMC Microbiology 2:33. 
231 Garrett AJ. 1969. The effect of magnesium ion deprivation on the synthesis of mucopeptide and its precursors in Bacillus subtilis. The Biochemical Journal $115: 419-430$.

234 Heckels JE, Lambert PA, Baddiley J. 1977. Binding of magnesium ions to cell walls of Journal 162:359-365.

237 Jacobsen H. 1907. Ueber einen richtenden Einfluss beim Wachstum gewisser

238 Bakterien in Gelatine. Zentr. Bakt. Parasitenk. II:53-64.

239 Kearns DB, Losick R. 2005. Cell population heterogeneity during growth of Bacillus $240 \quad$ subtilis. Genes \& Development 19:3083-3094.

241 Kirkman T. 1996. Statistics to use.

242 Lazarevic V, Margot P, Soldo B, Karamata D. 1992. Sequencing and analysis of the 243 Bacillus subtilis lytRABC divergon: A regulatory unit encompassing the 244 structural genes of the $\mathrm{N}$-acetylmuramoyl-L-alanine amidase and its modifier. Journal of General Microbiology 138:1949-1961.

Murray T, Popham DL, Setlow P. 1998. Bacillus subtilis cells lacking penicillin-binding protein 1 require increased levels of divalent cations for growth. Journal of Bacteriology 180:4555-4563.

Nan B, McBride MJ, Chen J, Zusman DR, Oster G. 2014. Bacteria that Glide with Helical Tracks. Current Biology 24:R169-R173.

251 Rogers HJ, Thurman PF. 1978. Temperature-sensitive nature of the rodB maturation 252 in Bacillus subtilis. Journal of Bacteriology 133:298-305.

253 Rogers HJ, Thurman PF, Buxton RS. 1976. Magnesium and anion requirements of 254 rodB mutants of Bacillus subtilis. Journal of Bacteriology 125:556-564.

255 Schindelin J, Arganda-Carreras I, Frise E, Kaynig V, Longair M, Pietzsch T, Preibisch S, 256 Rueden C, Saalfeld S, Schmid B et al. 2012. Fiji: an open-source platform for 257 biological-image analysis. Nature Methods 9:676-682. 
258 Sergent E. 1906. Des tropismes du "Bacterium zopfii" Kurth. Premiere note. Ann. 259 inst. Pasteur:1005-1017.

260 Sergent E. 1907. Des tropismes du “Bacterium zopfii” Kurth. Deuxieme note. Ann. 261 inst. Pasteur:842-850.

262 Smith TJ, Blackman SA, Foster SJ. 2000. Autolysins of Bacillus subtilis: multiple 263 enzymes with multiple functions. Microbiology 146:249-262.

264 Stackebrandt E, Keddie RM, Jones D. 2006. The Genus Kurthia. In: Dr MDP, Falkow S, 265 Rosenberg E, Schleifer K-H, Stackebrandt E eds. The Prokaryotes. Springer US, $266 \quad 519-529$.

267 Stanier RY. 1942. A Note on Elasticotaxis in Myxobacteria. Journal of Bacteriology $268 \quad 44: 405-412$

269 Stratford JP, Woodley MA, Park S. 2013. Variation in the Morphology of Bacillus 270 mycoides Due to Applied Force and Substrate Structure. PLOS ONE 8:e81549.

271 Tiyanont K, Doan T, Lazarus MB, Fang X, Rudner DZ, Walker S. 2006. Imaging 272 peptidoglycan biosynthesis in Bacillus subtilis with fluorescent antibiotics. 273 Proceedings of the National Academy of Sciences of the United States of $274 \quad$ America 103:11033-11038.

275 Turchi L, Santini T, Beccari E, Di Franco C. 2012. Localization of new peptidoglycan at 276 poles in Bacillus mycoides, a member of the Bacillus cereus group. Archives 277 of Microbiology 194:887-892. 


\section{Figure 1}

Microscopic morphology of $B$. mycoides and $B$. subtilis under compression.
A) Cells from liquid culture were applied to the bottom of an agarose pad compressed between plastic coverslips in a MatTek dish. Black arrows indicate direction of compression throughout. B) Striations visible in agar surfaces. C) Montages of timelapses of $B$. mycoides, B. subtilis PY79, and $B$. subtilis $\sigma^{\mathrm{D}}$ ::tet. Note the striations visible in the agarose running perpendicular to the direction of compression. 
A

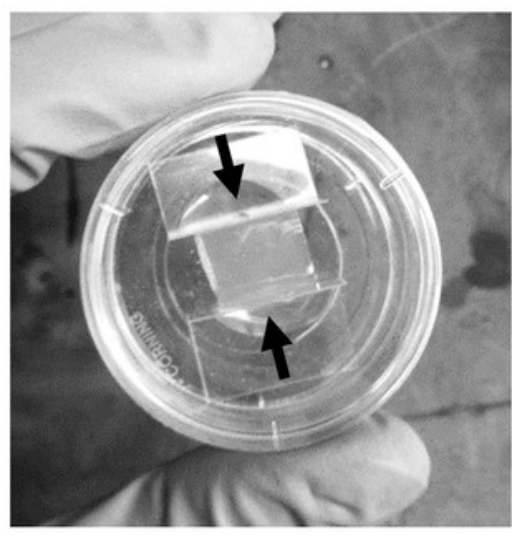

C

B. mycoides
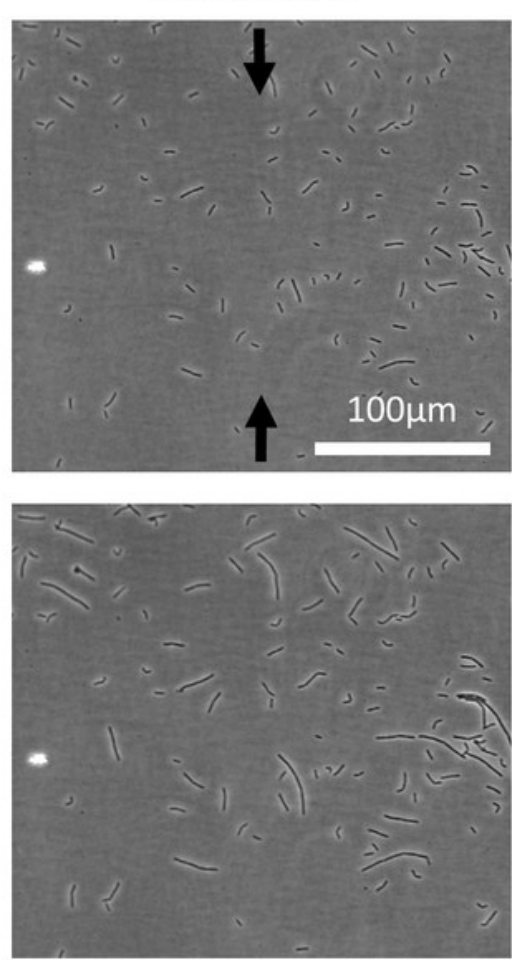

$2 \mathrm{hrs}$

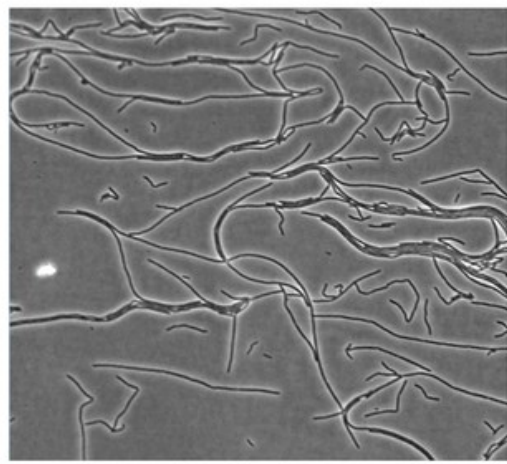

$4 \mathrm{hrs}$

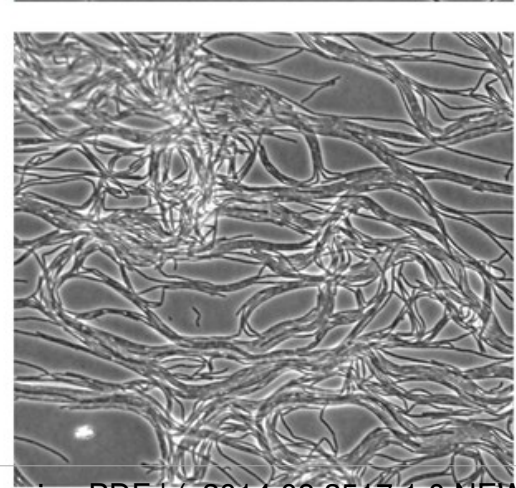

$6 \mathrm{hrs}$

PeerJ reviewing PDF | (v2014:08:2517:1:0:NEW 3 Sep 2014)

B

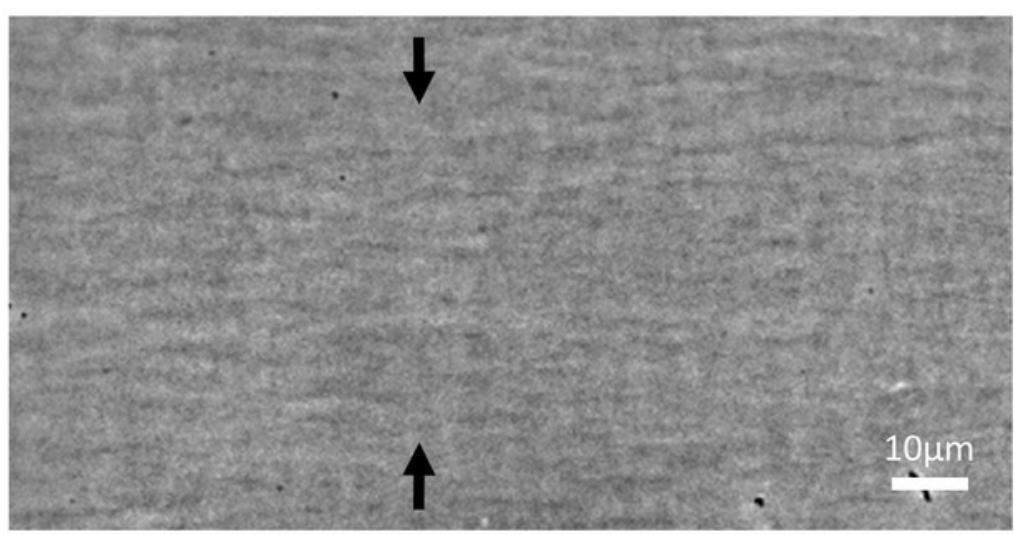

B. subtilis PY79
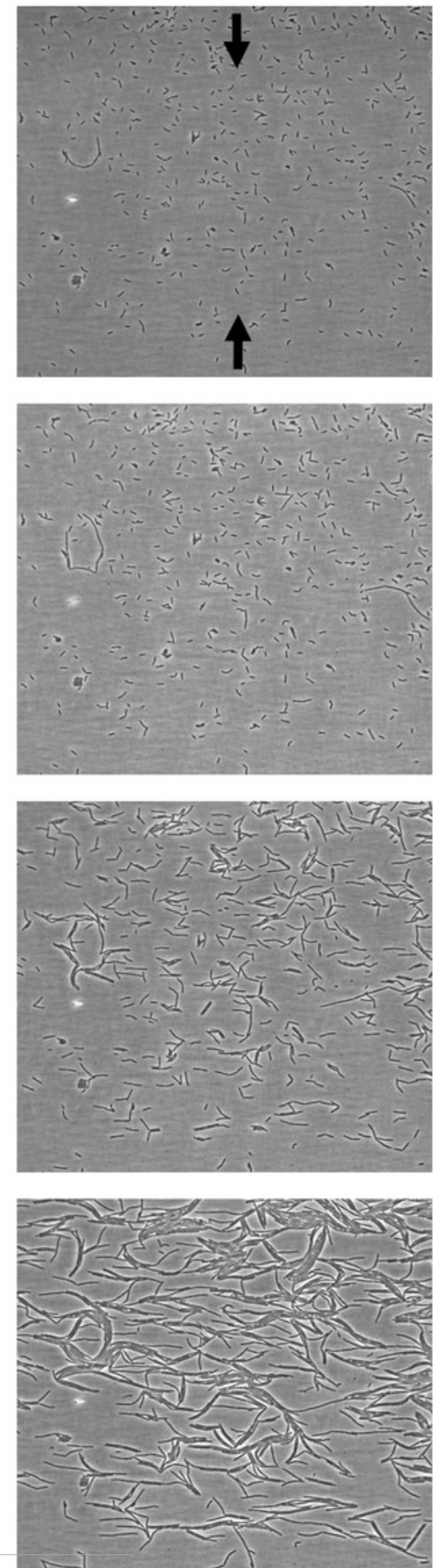

B. subtilis $\sigma \mathrm{D}:$ :tet
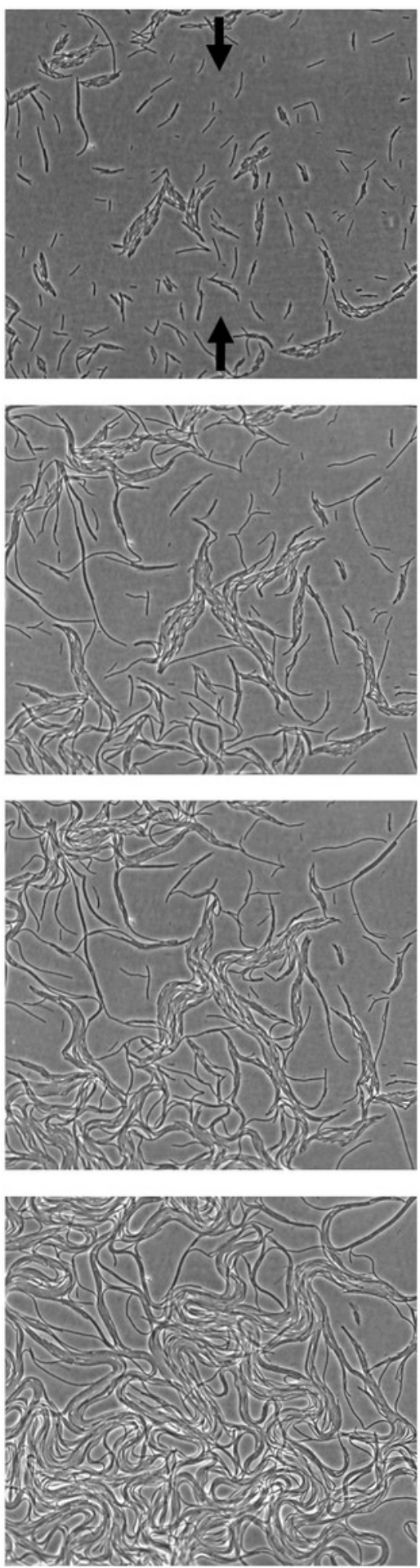


\section{Figure 2}

B. mycoides and $B$. subtilis colony morphology under compression.

A) A microtiter plate inoculated with B. mycoides and B. subtilis. The two white bars at the top of the image of the plate are polystyrene spacers, totaling $4.8 \%$ of the plate height. Black arrows indicate direction of compression throughout. B) Representative images of $B$. subtilis PY79 and $\sigma D$ ::tet colonies grown on compressed agar with varying EDTA concentrations. Scale bar, $1 \mathrm{~cm}$. C) Plot of colony shape ratio (ie, colony measurement perpendicular to the dimension of compression/colony measurement parallel to the dimension of compression) as it varies with EDTA concentration. D) Same as in C but with axes scaled to emphasize relative effect of PY79 and $\sigma \mathrm{D}:$ :tet, individual data points removed, and 95\% $\mathrm{Cl}$ error bars added. The $\sigma \mathrm{D}:$ :tet data has been shifted by $2 \mathrm{x}$-axis units to better display the error bars. For each condition, $n>11$. Source data for this figure can be found in supplementary dataset 1 . 

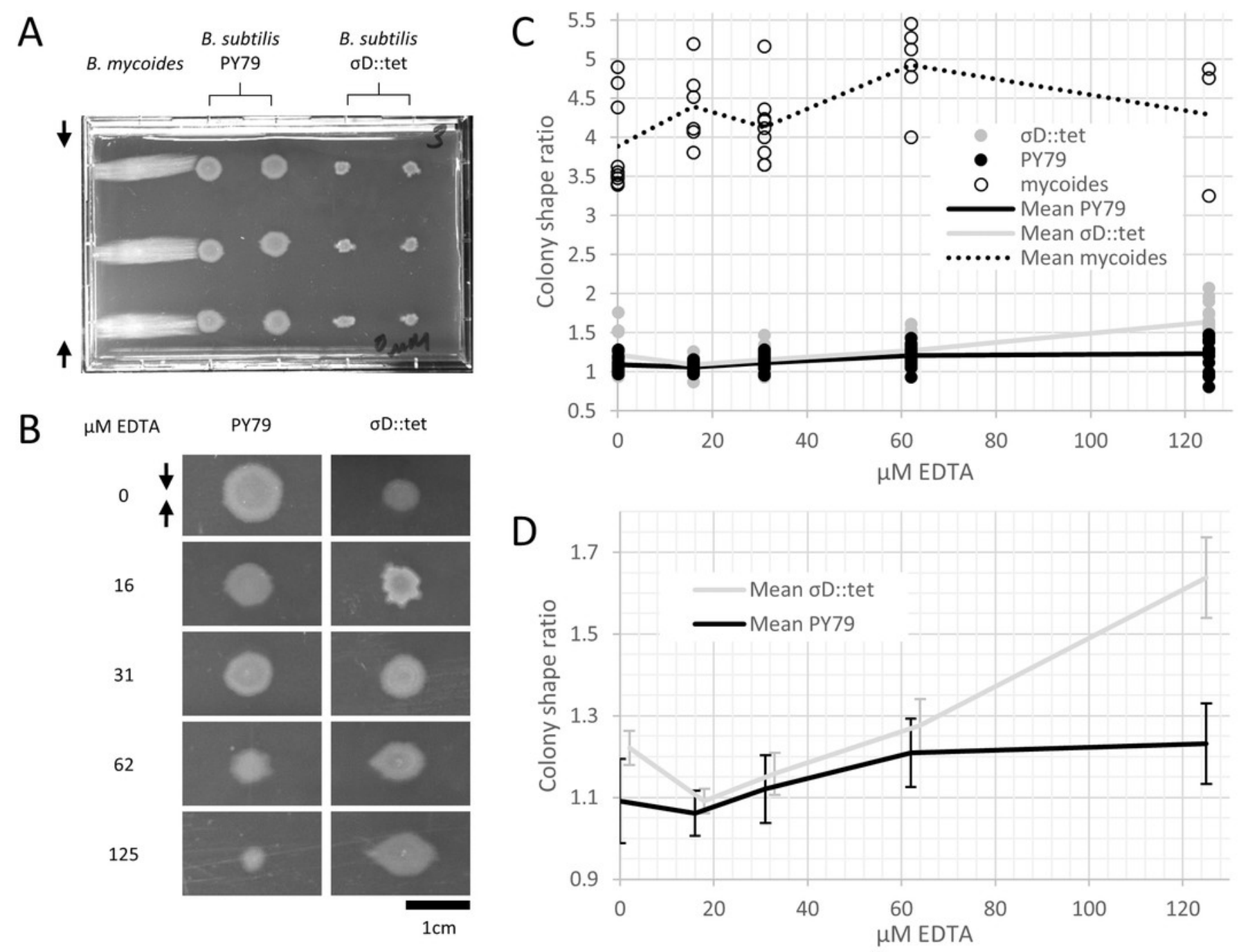


\section{Figure 3}

Cellular morphology with and without EDTA.

A-C) B. mycoides, B. subtilis PY79, and B. subtilis oD::tet, respectively, growing on LB agar containing $0 \mu \mathrm{M}$ EDTA. D-F) As above on $125 \mu \mathrm{M}$ EDTA. In all images, phase contrast

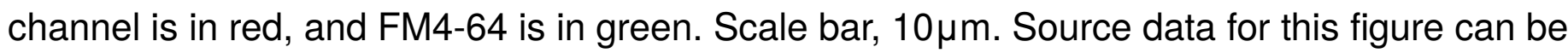
found in supplementary dataset 2 . 


\section{Figure 4}

Quantification of chain and cell lengths with and without EDTA.

A) Cell lengths of $B$. mycoides on $0 \mu \mathrm{M}$ (hollow bars) and $125 \mu \mathrm{M}$ EDTA (grey bars). B) Chain lengths of $B$. mycoides. C) Cell lengths of $B$. subtilis PY79. D) Chain lengths of $B$. subtilis PY79. E) Cell lengths of $B$. subtilis $\sigma D::$ tet. F) Chain lengths of $B$. subtilis $\sigma D::$ tet. Source data for this figure can be found in supplementary dataset 2 . 
A $\quad 0.3$

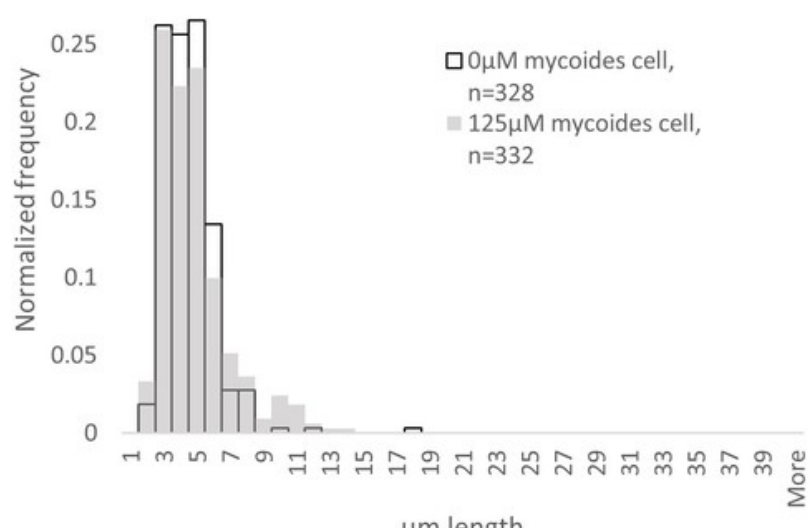

C

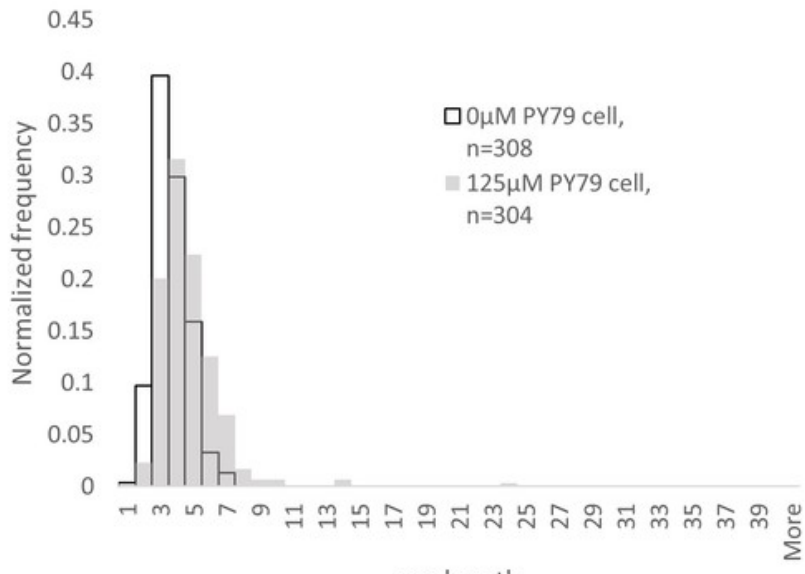

$E$

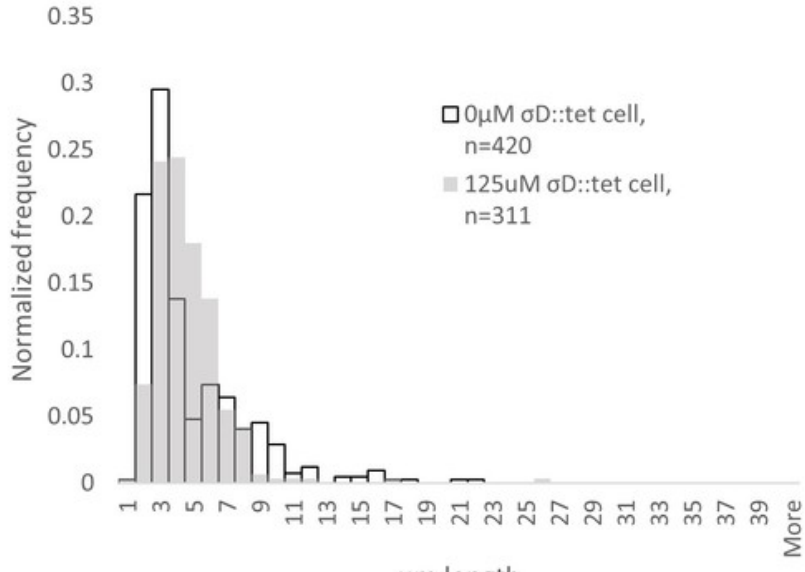

$\mu \mathrm{m}$ length
B

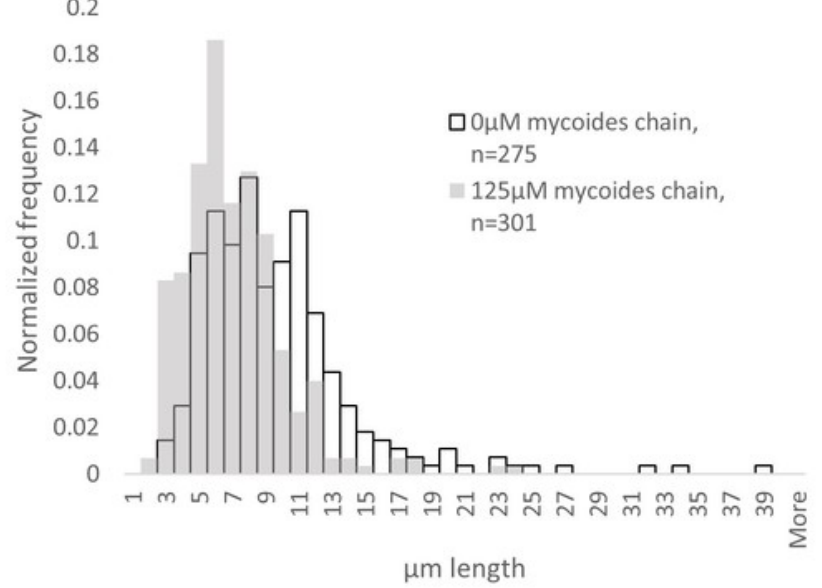

D $\quad 0.35$

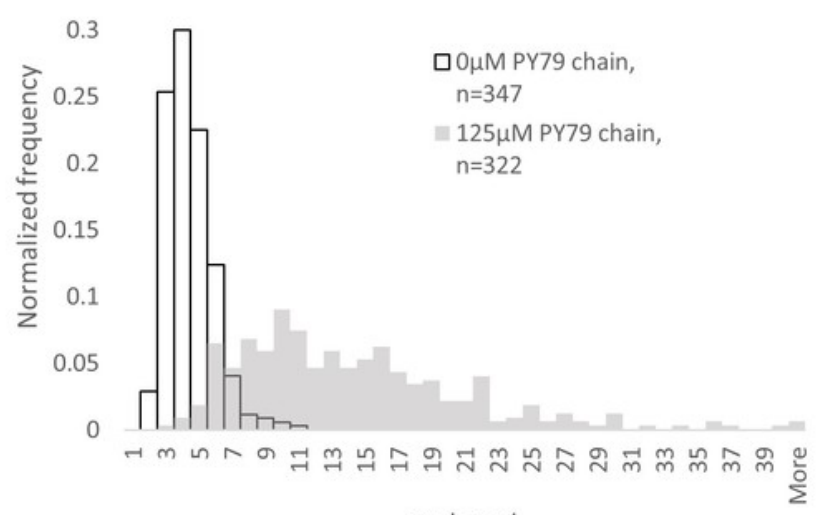
$\mu \mathrm{m}$ length

F

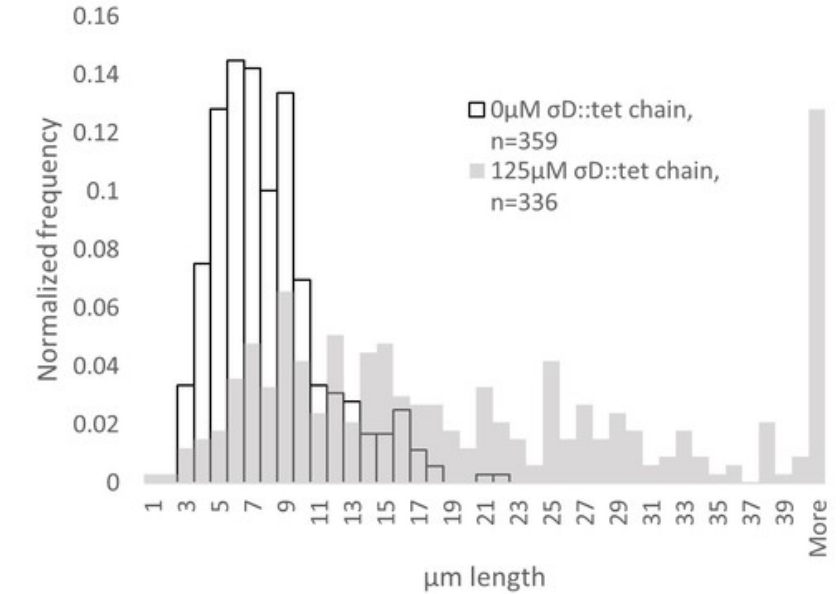




\section{Table 1 (on next page) \\ Strains used in this study}


Table 1. Strains used in this study

\begin{tabular}{|l|l|l|}
\hline Designation & Description & Reference \\
\hline B. subtilis PY79 & Lab strain & $\begin{array}{l}\text { Bacillus Genetic Stock } \\
\text { Center 1A747 }\end{array}$ \\
\hline B. subtilis $\sigma^{\text {D }:: t e t ~}$ & RL4169, DS323 & $\begin{array}{l}\text { Kearns and Losick, 2005 } \\
\text { (Kearns \& Losick, 2005) }\end{array}$ \\
\hline B. mycoides & & ATCC 6462 \\
\hline
\end{tabular}




\section{Table 2 (on next page)}

Properties of cell and chain length measurement distributions 
Table 2. Properties of cell and chain length measurement distributions

\begin{tabular}{|c|c|c|c|c|c|c|}
\hline & \multicolumn{3}{|c|}{ Cell length } & \multicolumn{3}{|c|}{ Chain length } \\
\hline & $\begin{array}{l}0 \mu \mathrm{M} \\
\text { EDTA } \\
\text { mean } \\
(\mu \mathrm{m})\end{array}$ & $\begin{array}{l}125 \mu \mathrm{M} \\
\text { EDTA } \\
\text { mean } \\
(\mu \mathrm{m})\end{array}$ & $\begin{array}{l}\text { KS test } \\
\text { maximum } \\
\text { difference }\end{array}$ & $\begin{array}{l}0 \mu \mathrm{M} \\
\text { EDTA } \\
\text { mean } \\
(\mu \mathrm{m})\end{array}$ & $\begin{array}{l}125 \mu \mathrm{M} \\
\text { EDTA } \\
\text { mean } \\
(\mu \mathrm{m})\end{array}$ & $\begin{array}{l}\text { KS test } \\
\text { maximum } \\
\text { difference }\end{array}$ \\
\hline $\begin{array}{l}B . \\
\text { mycoides }\end{array}$ & $\begin{array}{l}4.01 \text { (st } \\
\text { dev } 1.54)\end{array}$ & $\begin{array}{l}4.33 \text { (st } \\
\operatorname{dev} 2.04)\end{array}$ & $\begin{array}{l}D= \\
0.1044, P \\
=0.051\end{array}$ & $\begin{array}{l}9.19 \text { (st } \\
\text { dev } 4.81 \text { ) }\end{array}$ & $\begin{array}{l}6.60 \text { (st } \\
\text { dev 3.09) }\end{array}$ & $\begin{array}{l}D= \\
0.2959, P \\
=0.000\end{array}$ \\
\hline $\begin{array}{l}\text { B. subtilis } \\
\text { PY79 }\end{array}$ & $\begin{array}{l}3.18 \text { (st } \\
\operatorname{dev} 1.03 \text { ) }\end{array}$ & $\begin{array}{l}4.18 \text { (st } \\
\text { dev 1.93) }\end{array}$ & $\begin{array}{l}D= \\
0.2866, P \\
=0.000\end{array}$ & $\begin{array}{l}3.94 \text { (st } \\
\text { dev } 1.38)\end{array}$ & $\begin{array}{l}13.71 \text { (st } \\
\text { dev } 7.23 \text { ) }\end{array}$ & $\begin{array}{l}D= \\
0.8505, P \\
=0.000\end{array}$ \\
\hline $\begin{array}{l}\text { B. subtilis } \\
\sigma^{\mathrm{D}}: \text { :tet }\end{array}$ & $\begin{array}{l}4.23 \text { (st } \\
\text { dev } 3.20)\end{array}$ & $\begin{array}{l}4.12 \text { (st } \\
\operatorname{dev} 2.18 \text { ) }\end{array}$ & $\begin{array}{l}\mathrm{D}= \\
0.2413, \mathrm{P} \\
=0.000\end{array}$ & $\begin{array}{l}7.50 \text { (st } \\
\operatorname{dev} 3.36 \text { ) }\end{array}$ & $\begin{array}{l}21.99 \text { (st } \\
\text { dev } 18.1)\end{array}$ & $\begin{array}{l}D= \\
0.5633, P \\
=0.000\end{array}$ \\
\hline
\end{tabular}

